\title{
Cuprous oxide nanoparticles selectively induce apoptosis of tumor cells
}

This article was published in the following Dove Press journal:

International Journal of Nanomedicine

25 May 2012

Number of times this article has been viewed

\author{
Ye Wang ${ }^{1,2 *}$ \\ Xiao-Yuan $\mathrm{Zi}^{1 *}$ \\ Juan Su' \\ Hong-Xia Zhang' \\ Xin-Rong Zhang ${ }^{3}$ \\ Hai-Ying Zhu' \\ Jian-Xiu Li' \\ Meng Yin ${ }^{3}$ \\ Feng Yang ${ }^{3}$ \\ Yi-Ping $\mathrm{Hu}^{\prime}$ \\ 'Department of Cell Biology, ${ }^{2}$ School \\ of Clinical Medicine, ${ }^{3}$ Department \\ of Pharmaceuticals, Second Military \\ Medical University, Shanghai, \\ People's Republic of China \\ *Authors contributed equally
}

Correspondence: Yiping Hu Department of Cell Biology, Second Military Medical University, 800 XiangYin Road, Shanghai, 200433, People's Republic of China

Tel +86 2l 81870943

Fax +86 21 81870948

Email yphu@smmu.edu.cn

Feng Yang

Department of Pharmaceuticals, Second Military Medical University, 325 Guo-he Road, Shanghai 200433,

People's Republic of China

Tel +86 2I 8187 I219

$\mathrm{Fax}+862181871235$

Email yangfengI $008 @ 126 . c o m$

\begin{abstract}
In the rapid development of nanoscience and nanotechnology, many researchers have discovered that metal oxide nanoparticles have very useful pharmacological effects. Cuprous oxide nanoparticles (CONPs) can selectively induce apoptosis and suppress the proliferation of tumor cells, showing great potential as a clinical cancer therapy. Treatment with CONPs caused a G1/G0 cell cycle arrest in tumor cells. Furthermore, CONPs enclosed in vesicles entered, or were taken up by mitochondria, which damaged their membranes, thereby inducing apoptosis. CONPs can also produce reactive oxygen species (ROS) and initiate lipid peroxidation of the liposomal membrane, thereby regulating many signaling pathways and influencing the vital movements of cells. Our results demonstrate that CONPs have selective cytotoxicity towards tumor cells, and indicate that CONPs might be a potential nanomedicine for cancer therapy.
\end{abstract}

Keywords: nanomedicine, selective cytotoxicity, apoptosis, cell cycle arrest, mitochondriontargeted nanomaterials

\section{Introduction}

Nanoscience and nanotechnology have advanced greatly in recent years, and a large amount of research has focused on determining the properties and potential functions of nanomaterials. ${ }^{1-3}$ Nanomaterials show many unique and useful properties and can be applied in the areas of medicine, biology, and life science research. ${ }^{4-8}$ Nanomaterials have distinct magnetic properties, a large surface-to-volume ratio, and fluorescence, among others. They play important roles, such as developers, drug carriers, and tracers. ${ }^{9-14}$ Research has also shown that nanoparticles can affect the functions of cells and biomolecules. Nanomaterials can be toxic to cells and harmful to humans and other organisms. Many papers have reported that $\mathrm{ZnO}, \mathrm{TiO}_{2}, \mathrm{Ag}$, iron core-gold shell nanoparticles, and Au nanorods ${ }^{15-18}$ can specifically induce the apoptosis of tumor cells. These results agree well with the idea in traditional Chinese medicine (TCM) that "poisonous drugs sometimes can be used to treat serious and stubborn diseases." The TCM text, Shen Nong's Herbal, describes a medicine containing azurite ore, a copper mineral that has potential antitumor properties. Arsenic trioxide, another traditional Chinese medicine, has the same antitumor property, and it has been used to treat acute promyelocytic leukemia successfully. ${ }^{19-21}$ Although Shen Nong's Herbal describes both as cancer agents, azurite ore, in particular, shows poor solubility in water, making it difficult to investigate its antitumor property directly. However, nanoscience and nanotechnology methods offer a chance to solve this challenging issue.

CONPs are a new type of p-type semiconductor, have active electron-cavity pairs and good catalytic activity, and have been extensively applied in various fields, such 
as electrochemistry and physics. ${ }^{22-26}$ However, only a few studies have focused on the biological effects of CONPs, which are important in understanding the biological activity of nanomaterials. CONPs containing copper might also have pharmacological functions similar to those of azurite ore. Furthermore, cuprous oxide can bind to the hydrosulfide group, as arsenic trioxide does. We predict that CONPs may show therapeutic efficacy against cancer. However, the potential anticancer properties of CONPs remain an undeveloped area that is of medical interest.

In this study, we prepared CONPs to explore their pharmacological effects on cancerous HeLa cells, melanoma cells YUMAC, normal human 293T cells, and mouse embryonic fibroblast (MEF) cells. We discover that CONPs could selectively induce apoptosis and suppress the proliferation of tumor cells. From the transmission electron microscopy images, we found that CONPs could target the mitochondria and cause damage to their membranes. Furthermore, we carried out lipid peroxidation measurements and a dithiothreitol (DTT) protection experiment to test the effects of ROS on apoptosis. Our data show that CONPs have the potential for use in anticancer therapy.

\section{Material and methods Preparation of CONPs}

All of the chemical reagents used in this experiment were of analytical grade. CONPs were synthesized as follows: First, $0.35 \mathrm{~mL}$ of $0.1 \mathrm{M} \mathrm{CuSO}_{4}$ (aq) was added to $3 \mathrm{~mL}$ of $0.1 \mathrm{M}$ cetyltrimethylammonium bromide (CTAB) (aq) in a test tube, and the solutions were allowed to mix for about 5 minutes. Then, $10 \mathrm{~mL}$ of fresh, chilled $0.04 \mathrm{M} \mathrm{NaBH}_{4}$ (aq) was added to the mixture. The mixture was stirred at $26^{\circ} \mathrm{C}-28^{\circ} \mathrm{C}$. After approximately 18 hours, the mixture turned yellow. Finally, the product was harvested from the solution by centrifugation at $12,000 \mathrm{rpm}$ for 15-20 minutes and washed several times with ethanol and deionized water. After removing the supernatant, the product was dried in a vacuum dryer for $12-18$ hours at $50^{\circ} \mathrm{C}$. The dried product was stored in a hermetic container at $4^{\circ} \mathrm{C} \cdot 22,27$

\section{Characterization of CONPs}

The prepared CONPs were characterized by powder X-ray diffraction (XRD) and transmission electron microscopy (TEM). The XRD pattern was obtained using a D/MAXrB X-ray powder diffractometer (Rigaku, Japan) using $\mathrm{Cu}$ $\mathrm{Ka}$ radiation (average wavelength is $0.15418 \mathrm{~nm}$ ), and the operation voltage and current were maintained at $30 \mathrm{kV}$ and $30 \mathrm{~mA}$, respectively. The morphologies of the CONPs were examined by TEM at an acceleration voltage of $100 \mathrm{kV}$. Dynamic light scattering size analyses of CONPs in suspensions was carried out using a Nano HT Zetasizer (Malvern Instruments, Malvern, UK). The UV-visible spectra of the dispersions were obtained with a visible/UV-spectrophotometer (UV2450, Shimadu, Japan). Fourier transform infrared (FTIR) spectra of the samples were recorded using an AlphaT spectrometer (Nicolet Nexus470, Nicolet, USA).

\section{Cytotoxicity assay}

The HeLa cells, 293T cells, and MEF cells used in this research were grown in Dulbecco's modified Eagle's medium (DMEM), and the melanoma cell line YUMAC were grown in Opti-MEM (Gibco ${ }^{\mathrm{TM}}$, Invitrogen Corp, Calsbad, CA). Both mediums were supplemented with $2 \mathrm{mg} / \mathrm{mL}$ sodium bicarbonate, $4.5 \mathrm{mg} / \mathrm{mL}$ glucose, $100 \mu \mathrm{g} / \mathrm{mL}$ streptomycin sulfate, $40 \mu \mathrm{g} / \mathrm{mL}$ gentamicin, $100 \mathrm{U} / \mathrm{mL}$ penicillin. DMEM were supplemented with $10 \%$ (vol/vol) heat-inactivated fetal calf serum, and the Opti-MEM were 5\%. An environment of humidified air containing $5 \% \mathrm{CO}_{2}$ was maintained at $37^{\circ} \mathrm{C}$. HeLa cells, 293T cells, and melanoma cell line YUMAC were stored by our laboratory. The original source of the HeLa cells and 293T cells was the Cell Bank of Typical Culture Collection (Chinese Academy of Sciences, Shanghai, China). The YUMAC cells were provided generously by Yale University School of Medicine (New Haven, CT). The MEF cells were obtained from day 13 C57BL/6 mouse embryos. To evaluate the cytotoxicity of the CONPs, cells in the $\log$ phase were seeded onto a 96 -well culture plate with 2000 cells per well and incubated at $37^{\circ} \mathrm{C}$ in a $\mathrm{CO}_{2}$ incubator for 24 hours until the cells adhered to the plate. Serial dilutions of CONPs were added, and after 48 hours, cell viability was measured using the 3-(4,5-di-methylthiazol2yl)-2,5-diphenyl tetrazolium bromide (MTT) assay. For this assay, $200 \mu \mathrm{L}$ of $5 \mathrm{mg} / \mathrm{mL}$ MTT solution (prepared in medium without blood serum) was added to the cells in the culture and incubated at $37^{\circ} \mathrm{C}$ in a $\mathrm{CO}_{2}$ incubator for 4 hours. Dimethyl sulfoxide was then used to dissolve the formazan crystals. Finally, the absorbance was measured at $570 \mathrm{~nm}$ using an ELISA plate reader. ${ }^{28}$

\section{Apoptosis detection by Annexin V staining}

Cells in the $\log$ phase were seeded onto a 6-well culture plate at a density of $1 \times 10^{5}$ cells per well and incubated at $37^{\circ} \mathrm{C}$ in a $\mathrm{CO}_{2}$ incubator in the presence of CONPs. The cells were treated with 0,10 , or $20 \mu \mathrm{g} / \mathrm{mL}$ CONPs. After 48 hours, apoptosis and necrosis were analyzed with the 
Annexin V-fluorescein isothiocyanate apoptosis detection kit 1 following the manufacturer's instructions. The samples were analyzed using a BD FACSCanto instrument (BD Biosciences, Franklin Lakes, NJ).

\section{Flow cytometry of cell cycle progression}

The cells were harvested using $0.25 \%$ trypsin with $1 \mathrm{mM}$ of EDTA solution and fixed for 12 hours in $70 \%$ ethanol at $4^{\circ} \mathrm{C}$. The fixed cells were then centrifuged at $3000 \mathrm{rpm}$ for 15 minutes to remove the ethanol thoroughly. The cells were then washed twice with $3 \mathrm{~mL}$ of phosphate-buffered saline (PBS), resuspended in $1 \mathrm{~mL}$ of propidium iodide (PI) staining solution, and incubated for 15 minutes at room temperature. The staining solution consisted of $20 \mu \mathrm{g} / \mathrm{mL}$ PI and $0.2 \mathrm{mg} / \mathrm{mL}$ RNase A in PBS. The samples were subsequently analyzed using a BD FACSCanto instrument (BD Biosciences, Franklin Lakes, NJ).

\section{Transmission electron microscopy (TEM) assay}

The HeLa cells were grown in a large petri dish. When cells had adhered to the dish, a solution of CONPs was added to a final concentration of $30 \mu \mathrm{g} / \mathrm{mL}$. The cells were incubated at $37^{\circ} \mathrm{C}$ in a $\mathrm{CO}_{2}$ incubator. After approximately 4 hours, the cells were harvested, washed twice with PBS, and incubated with $4^{\circ} \mathrm{C}$ formaldehyde overnight to fix the cells. The cells were then dehydrated with increasing concentrations of ethanol $(50 \%, 60 \%, 70 \%, 80 \%, 90 \%$, and $100 \%)$ for 15 minutes each, stained with $2 \%$ uranyl acetate in $70 \%$ ethanol overnight at room temperature, and then embedded in Epon. The embedded samples were sectioned into 60-nm-thick slices using a sliding ultramicrotome. Thin sections supported by copper grids were examined using a Hitachi TEM system operated at $100 \mathrm{kV}$ (Hitachi, Tokyo, Japan).

\section{Dithiothreitol protection experiment}

ROS may play an important role in lipid peroxidation and the suppression of cell growth. Dithiothreitol (DTT) is a hypotoxic reducing agent that can inactivate ROS and protect the hydrosulfide groups of protein. The cells were cultured as described above in the cytotoxicity assay section, except $20 \mu \mathrm{g} / \mathrm{mL}$ of fresh DTT was added to the cell medium or lipid peroxidation reaction mixture. After 48 hours, an MTT assay was used to determine the extent of the protective effects of DTT.

\section{Lipid peroxidation measurement}

The free-radical modulation activity of CONPs was determined using a lipid peroxidation assay. Briefly, lipid peroxidation was induced in liposomes prepared from soybean lecithin and cholesterol by ultrasonic irradiation. The CONPs were added to the prepared liposomes and the control samples were supplemented with PBS. The samples were incubated at $37^{\circ} \mathrm{C}$ for 1 hour in a dark incubator. The reaction was inhibited by adding an equal volume of stop solution $(0.25 \mathrm{M} \mathrm{HCl}, 1.5 \%$ (wt/vol) trichloroacetic acid, and $0.375 \%$ (wt $/ \mathrm{vol}$ ) thiobarbituric acid). These reaction mixtures were boiled for 15 minutes, cooled, and then centrifuged at $12,000 \mathrm{rpm}$ for 15 minutes. The absorbance of the resulting solution was measured at $532 \mathrm{~nm} .^{15,28}$

\section{Statistical analysis}

Data were analyzed using SigmaPlot 10.0 software (Systat Software Inc, San Jose, CA). Statistical differences between the control and treatment groups for the in vitro experiments comparing the toxicity of the CONPs were determined using an analysis of paired $t$-test with significance set at $P<0.05$.

\section{Results and discussion Characterization of CONPs}

The XRD patterns (Figure 1) showed that the CONPs were crystalline, and the diffraction pattern and interplanar spacing of the CONPs were similar to those in the standard diffraction pattern of cuprous oxide. ${ }^{22}$ Furthermore, no characteristic peaks of impurities were detected, suggesting that highquality CONPs were obtained. The UV-vis spectrum of the CONPs showed a wide absorption band between $200 \mathrm{~nm}$ and $500 \mathrm{~nm}$ (Figure 2). Figure 3 presents the FTIR spectra of the CONPs, showing their composition and quality. The band at $624 \mathrm{~cm}^{-1}$ correlates with the stretching vibrations of cuprous oxide. The bands at approximately $2922 \mathrm{~cm}^{-1}$ and $1373 \mathrm{~cm}^{-1}$ are probably due to the carbonate moieties, water,

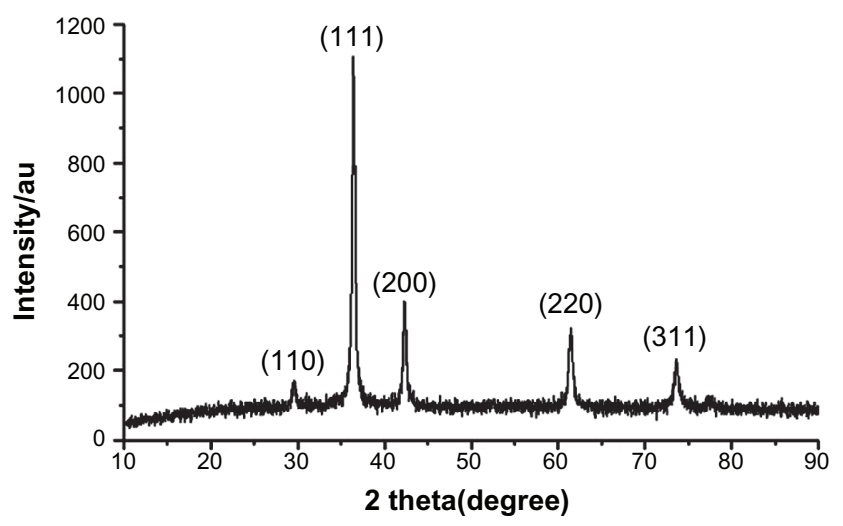

Figure I X-ray patterns of the CONPs.

Note: Results revealed the crystal structure of the CONPs, and no characteristic peaks of impurities were detected.

Abbreviation: CONPs, cuprous oxide nanoparticles. 


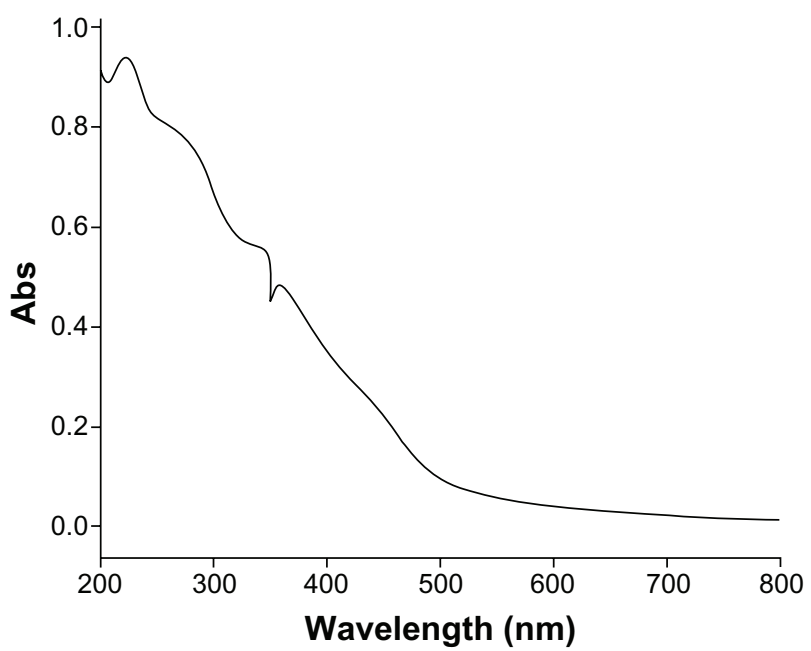

Figure 2 UV-vis spectra of the CONPs.

Note: CONPs were dissolved in deionized water and deionized water was used as a reference.

Abbreviation: CONPs, cuprous oxide nanoparticles.

or other organic compounds in the air that were adsorbed by the CONPs, as these bands are generally observed when FTIR samples are measured in air. ${ }^{15}$ The TEM images showed that the CONPs were all spherical and homogeneous (Figure 4). The diameter of the CONPs in the suspensions ranged from approximately $40 \mathrm{~nm}$ to $110 \mathrm{~nm}$ (Figure S1). From our characterization of the CONPs, we can see that the CONPs prepared in our experiment were of good quality.

\section{Cytotoxicity assay}

In TCM, copper or cuprous compounds have been used to treat cancer and other diseases for thousands of years. ${ }^{29}$
These cuprous compounds may have properties similar to those of another effective antitumor drug, arsenic trioxide. ${ }^{19-21}$ Copper is a known heavy metal that is toxic to human cells and has been shown to have significant side effects on the human body. However, with the development of nanoscience and nanotechnology, research has shown that nanoparticles can target specific organs, have a lower toxicity against the whole organism, and have good dissolubility in water. Therefore, CONPs may be an ideal combination of TCM and nanoscience. Despite the strong potential of CONPs to be a novel therapy tool, no study has reported on the interactions of CONPs in the relevant in vitro or in vivo biological settings.

To solve this fundamental issue and to investigate the potential uses of CONPs as cancer therapeutics, an MTT assay was used to evaluate how CONPs affect the viability of HeLa cells and melanoma cells with normal human 293T cells and MEF cells as control. CONPs exhibited dose-dependent cytotoxicity in HeLa cells with a half-maximal inhibitory concentration $\left(\mathrm{IC}_{50}\right)$ of $8.28 \mu \mathrm{g} / \mathrm{mL}$, and in melanoma cells with $\mathrm{IC}_{50}$ of $1.533 \mu \mathrm{g} / \mathrm{mL}$, whereas the $\mathrm{IC}_{50}$ values in $\mathrm{MEF}$ cells and $293 \mathrm{~T}$ cells were $27.00 \mu \mathrm{g} / \mathrm{mL}$ and $14.22 \mu \mathrm{g} / \mathrm{mL}$, respectively. The cancerous HeLa cells and melanoma cells displayed a strikingly greater sensitivity to the CONPs than the normal human (293T) or mouse (MEF) cell lines did $(P<0.005)$ (Figure 5). At low concentrations, lower than $5 \mu \mathrm{g} / \mathrm{mL}$, there was a discriminative difference in the level of cytotoxicity between tumor cells and normal cells. Differential cytotoxicity is important because one of the

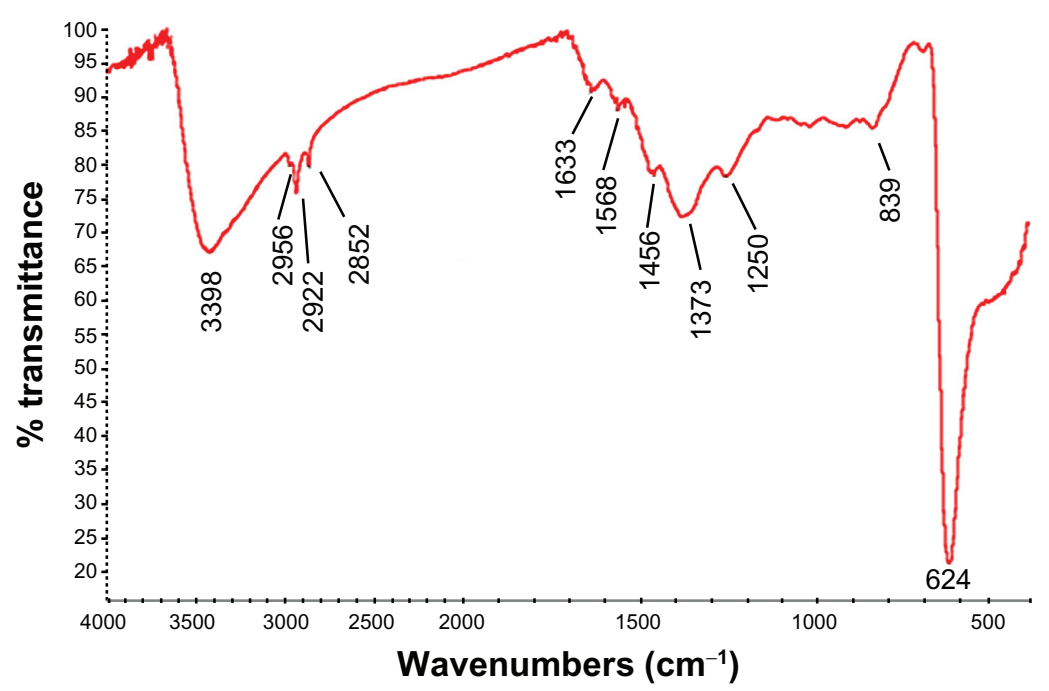

Figure 3 FTIR transmission spectra of the CONPs. The band at $624 \mathrm{~cm}^{-1}$ correlates to the stretching vibration of the CONPs.

Notes: Moreover, there were also some stretching bands. The other bands at $3398 \mathrm{~cm}^{-1}, 2992 \mathrm{~cm}^{-1}, 1373 \mathrm{~cm}^{-1}$, and $839 \mathrm{~cm}^{-1}$ are probably due to the carbonate moieties and water that are generally observed, when FTIR samples are measured in air.

Abbreviations: CONPs, cuprous oxide nanoparticles; FTIR, Fourier transform-infrared. 


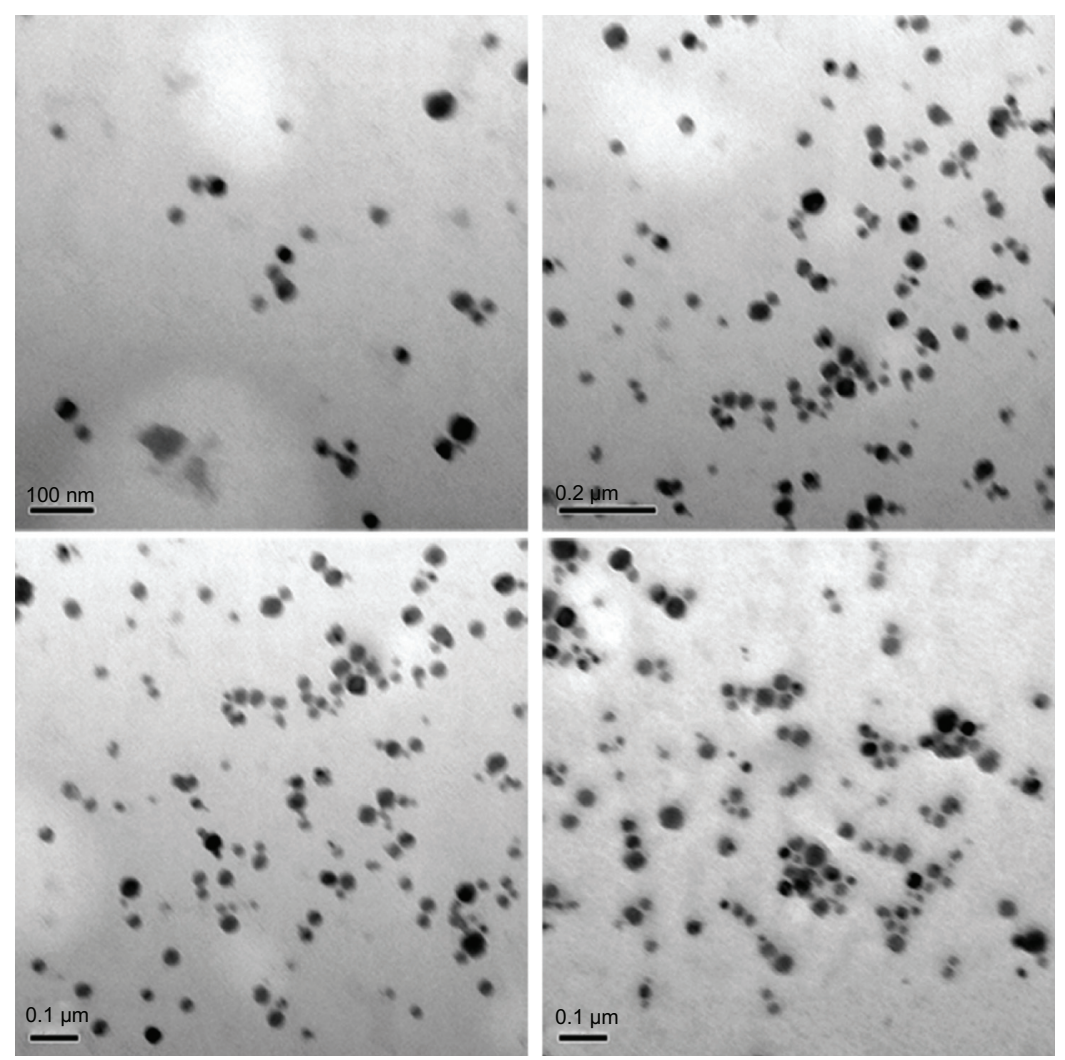

Figure 4 TEM images of the CONPs.

Note: The CONPs were all perfect spheres, and the mixtures were homogeneous.

Abbreviations: CONPs, cuprous oxide nanoparticles; TEM, transmission electron microscopy.

greatest challenges facing chemotherapy is the inability of anticancer drugs to distinguish effectively between tumor cells and normal cells. In our study, low concentrations of CONPs selectively killed tumor cells, suggesting that CONPs may be useful as a potential anticancer drug. In addition to CONPs, $\mathrm{ZnO}$ nanoparticles also have selective toxicity against human myeloblastic leukemia cells (HL60) and show less toxicity against normal peripheral blood mononuclear cells. ${ }^{15}$ Therefore, CONPs may have a potential utility in the treatment of cancer, as do $\mathrm{ZnO}$ nanoparticles. Research has also shown that iron core-gold shell NPs have cancer cell-specific cytotoxicity. ${ }^{16}$ Referring to the periodic table of elements, it is not difficult to understand these results. $\mathrm{Zn}$ (II) and $\mathrm{Cu}(\mathrm{I})$ have a similar extranuclear electron assignment, which may contribute to their similar properties. Therefore, we can conjecture that the chemical and physical properties of these nanomedicines provide the basis of their biological action. Furthermore, some research has reported that the tumor cells were unable to clear the nanoparticles, but this result was different in the normal cells. ${ }^{30}$ In our experiment, the inability to clear CONPs might be one of the mechanisms that caused CONPs to show selective cytotoxicity against tumor cells.

\section{Apoptosis and cell cycle progression}

Several studies have indicated that different nanoparticles can suppress cell viability by different mechanisms. Specific kinds of nanoparticles can induce apoptosis in cells, but other kinds of nanoparticles can make cells undergo necrosis. ${ }^{15,16,31}$ To investigate the mechanism of CONPs cytotoxicity, we performed flow cytometry to analyze the effects of CONPs on cell death and cell cycle. First, Annexin V- and PI-based apoptosis and necrosis discrimination assays were performed on $\mathrm{HeLa}$ and MEF cells exposed to $10 \mu \mathrm{g} / \mathrm{mL}$ and $20 \mu \mathrm{g} / \mathrm{mL}$ of CONPs for 48 hours (Figure 6). The results showed an increase in apoptosis in HeLa cells, which was dependent on the dose of CONPs, and a similar increase in necrosis was observed. However, decreased apoptosis and necrosis were observed in the MEF cells in accordance with the cytotoxicity assays. These results showed that CONPs have selective antitumor properties.

Apoptosis is a cell suicide mechanism that enables organisms to control cell numbers and to eliminate cells that threaten survival. The apoptotic cascade can be triggered through two major pathways. Extracellular signals, such as members of the tumor necrosis factor (TNF) family 


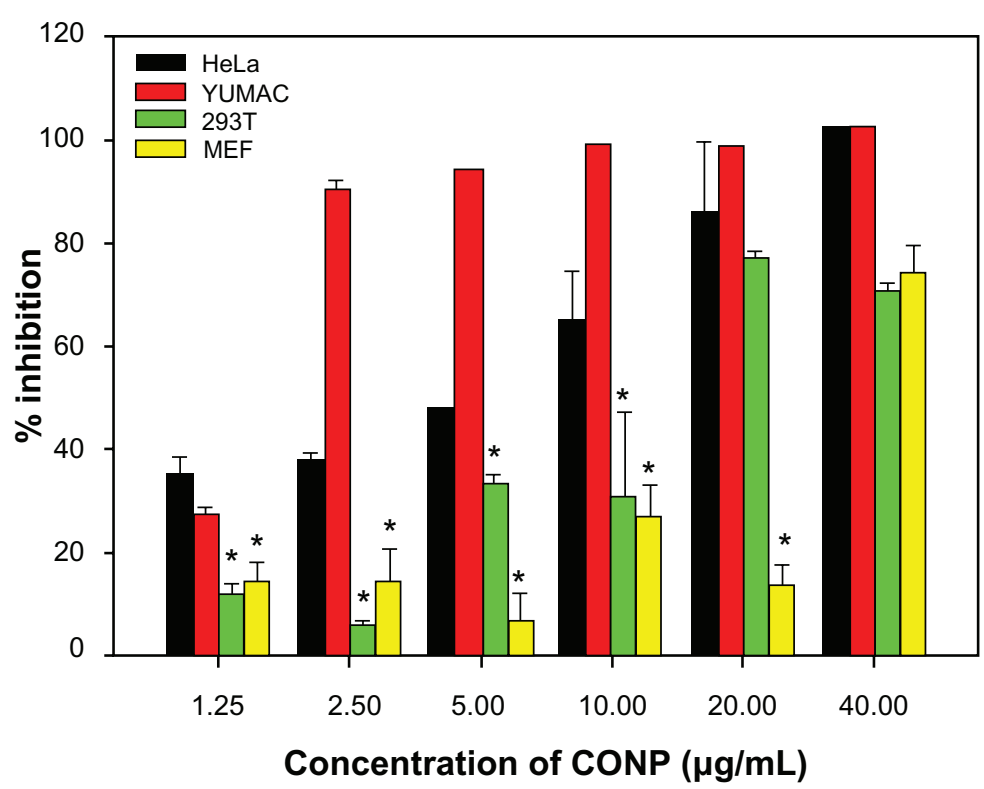

Figure 5 Differential cytotoxicity of CONPs on tumor cell (melanoma cells YUMAC), paired control tumor cell (HeLa), and normal cells (293T and MEF) detected by MTT assay. Notes: HeLa cells and melanoma cells were more sensitive, and the two normal cell lines (293T and MEF cells) were tolerant, especially at low concentrations. Cells were treated with the CONPs for 48 hours $(* P<0.005, \mathrm{n}=3$ ).

Abbreviations: CONPs, cuprous oxide nanoparticles; MEF, mouse embryonic fibroblast.

or the Fas/FasL pathway, can activate the receptor-mediated extrinsic pathway. Alternatively, stress signals, such as DNA damage, hypoxia, and loss-of-survival signals, may trigger the mitochondrial intrinsic pathway. ${ }^{32,33}$ CONPs are p-type semiconductors and have active electron-cavity pairs. CONPs can produce ROS, break disulfide bonds, and bind to the hydrosulfide group in proteins. Because of their fundamental chemical and physical properties, CONPs could exert oxidative stress on cells and cause membrane damage and DNA breaks. Because many proteins in the cell contain disulfide bonds or hydrosulfide groups, CONPs may target these proteins and influence their activity, thus
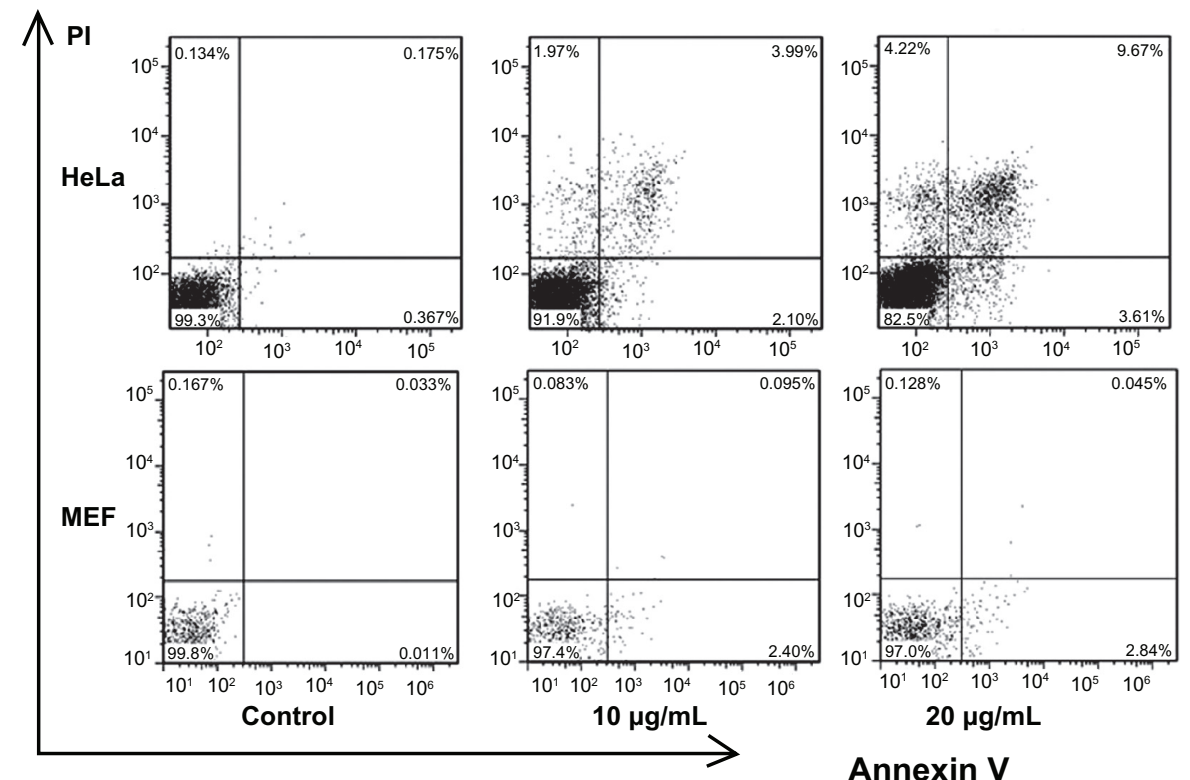

Figure 6 Flow cytometry analysis of HeLa and MEF cells treated with different concentrations of CONPs for 48 hours and then stained with Annexin V and PI.

Notes: Significant increases in apoptosis were observed in HeLa cells exposed to the $10 \mu \mathrm{g} / \mathrm{mL}$ and $20 \mu \mathrm{g} / \mathrm{mL}$ CONPs for 48 hours. However, decreased apoptosis was observed in the MEF cells. The upper-left quadrant in each panel shows the necrotic population, the upper-right quadrant shows the late apoptotic population, and the lowerright quadrant shows the early apoptotic population.

Abbreviations: CONPs, cuprous oxide nanoparticles; MEF, mouse embryonic fibroblast; PI, propidium iodine. 
regulating tumor-specific signal pathways, exhibiting specific pharmacological activity, or inducing the apoptosis of tumor cells, which were similar to the effects of arsenic trioxide. Moreover, cellular respiration is the basis of every vital movement in the cell. The electron transport chain performs an important role in cellular respiration and contains several protein complexes that have cuprous active centers. CONPs may also release cuprous ions and influence the electron transfer through the respiratory chain, causing tumor cells to lack energy and start the apoptotic pathway.

Cell cycle progression analysis was performed and showed that HeLa cells were arrested strongly by CONPs in a dose-dependent manner. Approximately 58\% of cells exposed to $10 \mu \mathrm{g} / \mathrm{mL}$ of CONPs and $80 \%$ of cells exposed to $20 \mu \mathrm{g} / \mathrm{mL}$ of CONPs were arrested in G1/G0 48 hours after CONPs exposure (Figure 7). Furthermore, the number of cells in S phase decreased as the concentration of CONPs increased. However, the iron-core gold-shell nanoparticles also suppressed cell proliferation and cells were delayed in S phase, ${ }^{16}$ whereas the cells exposed to CONPs were delayed in G1/G0. Furthermore, treatment with Ag nanoparticles caused a cell cycle arrest in G2/M phase, possibly due to the repair of damaged DNA. ${ }^{34}$ These results show that different nanoparticles have different effects on the cell cycle, which may be important in exploring the mechanism of their biological actions.
Our experimental data show that CONPs also suppressed the proliferation of tumor cells and caused a cell cycle arrest in G1/G0. These effects showed that CONPs might inhibit DNA replication. DNA replication relies on many factors, including the DNA replication machinery, cyclin/ cyclin-dependent kinase (CDK) complexes, the production of anti-oncogenes (such as p53), growth factor-mediated cellular signaling, and others. CONPs may influence one or more of these factors to suppress DNA replication. CONPs are a novel type of $\mathrm{p}$-type semiconductor that have active electron-cavity pairs and could produce ROS that upregulate p53-mediated cellular signaling, which may be a mechanism by which the cells are arrested in the G1/G0 phase. ${ }^{35}$ From the similar properties of cuprousion, we could infer that CONPs may also break disulfide bonds and bind to hydrosulfide groups. Because numerous proteins contain disulfide bonds and hydrosulfide groups, these proteins may be targets of the CONPs, which could explain how the CONPs influenced cell signaling. Moreover, disulfide bonds and hydrosulfide groups are also located on the cell membrane; therefore, CONPs might bind to the cell membrane and imitate contact inhibition to suppress cell proliferation.

\section{Transmission electron microscopy assay}

To determine the mechanism of apoptosis, it is essential to know whether the CONPs crossed the cell membrane. We therefore used TEM to analyze HeLa cells that had been

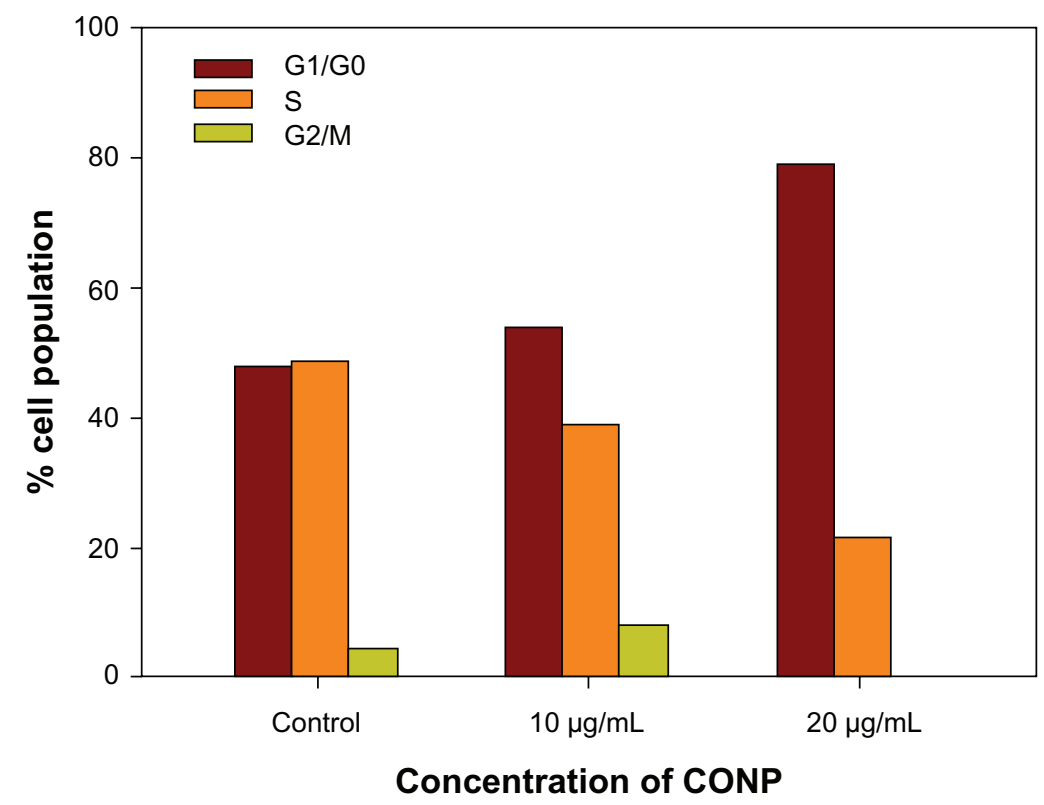

Figure 7 Cell cycle progression assay of HeLa cells treated with different concentrations of CONPs for 48 hours.

Notes: Proliferation of HeLa cells was strongly suppressed by CONPs in a dose-dependent manner. Cells were arrested in the GI/G0 phase after 48 hours of treatment and were less able to proliferate.

Abbreviation: CONPs, cuprous oxide nanoparticles. 
treated with $30 \mu \mathrm{g} / \mathrm{mL}$ CONPs for 3-4 hours. As shown in Figure 8(A), we observed that several CONPs were enclosed in small vesicles within the cells. In addition, numerous CONPs were found in the cytoplasm. The CONPs in the cytoplasm had two possible sources. First, the CONPs may have penetrated the cell membrane without breaking it. Alternatively, the CONPs were taken up by cells in small vesicles, but then they broke the membrane of the vesicles and were released into the cytoplasm. Furthermore, all the images showed that CONPs could not efficiently enter the nucleus, lysosomes, or endoplasmic reticulum. However, the CONPs could cause endoplasmic reticulum tumescence (Figure 8B).

It is important to note that the CONPs within the vesicles could target the mitochondria, enter the mitochondria, and cause their rupture (Figure 8E and F). How could the CONPs within the vesicles target the mitochondria? Referring to the TEM images, the whole process might be described as follows: The CONPs, which may adsorb the serum proteins in the medium, were taken up by the cells, which was mediated by special receptors and resulted in CONPs entering the cell in small vesicles. The vesicles containing the CONPs may express special proteins, which could bind to the mitochondrial outer membrane, that were transported in the cytoplasm and targeted the mitochondria. The membranes of the vesicles and the mitochondria would then fuse, and the CONPs would be released into the mitochondria. As we discussed previously, CONPs can produce ROS and may bind to proteins with hydrosulfide groups. The membrane of the mitochondria was broken by the CONPs immediately afterwards. Tumor cells may lose the ability to clear the nanoparticles that had been taken up by these cells. However, normal cells can clear the nanoparticles efficiently, ${ }^{30}$ and were resistant to the CONPs. The CONPs were therefore selectively toxic to the tumor cells and targeted the mitochondria. Alternatively, Figure 8A, C and D show that the outer membrane of the mitochondria invaginated at the surface touching the vesicles containing CONPs and pseudopodium-like structures, which might take up the vesicles and is similar to cell phagocytosis. Thereby, the phagocytosis of mitochondria might be observed in our TEM images, and the vesicles were actively taken up by the mitochondria. Further studies should be performed to determine the mechanism by which the CONPs entered the mitochondria.

Similarly, gold nanorods bound to CTAB could also target the mitochondria of tumor cells. However, gold nanorods bound to CTAB targeted the mitochondria without vesicles. ${ }^{30}$
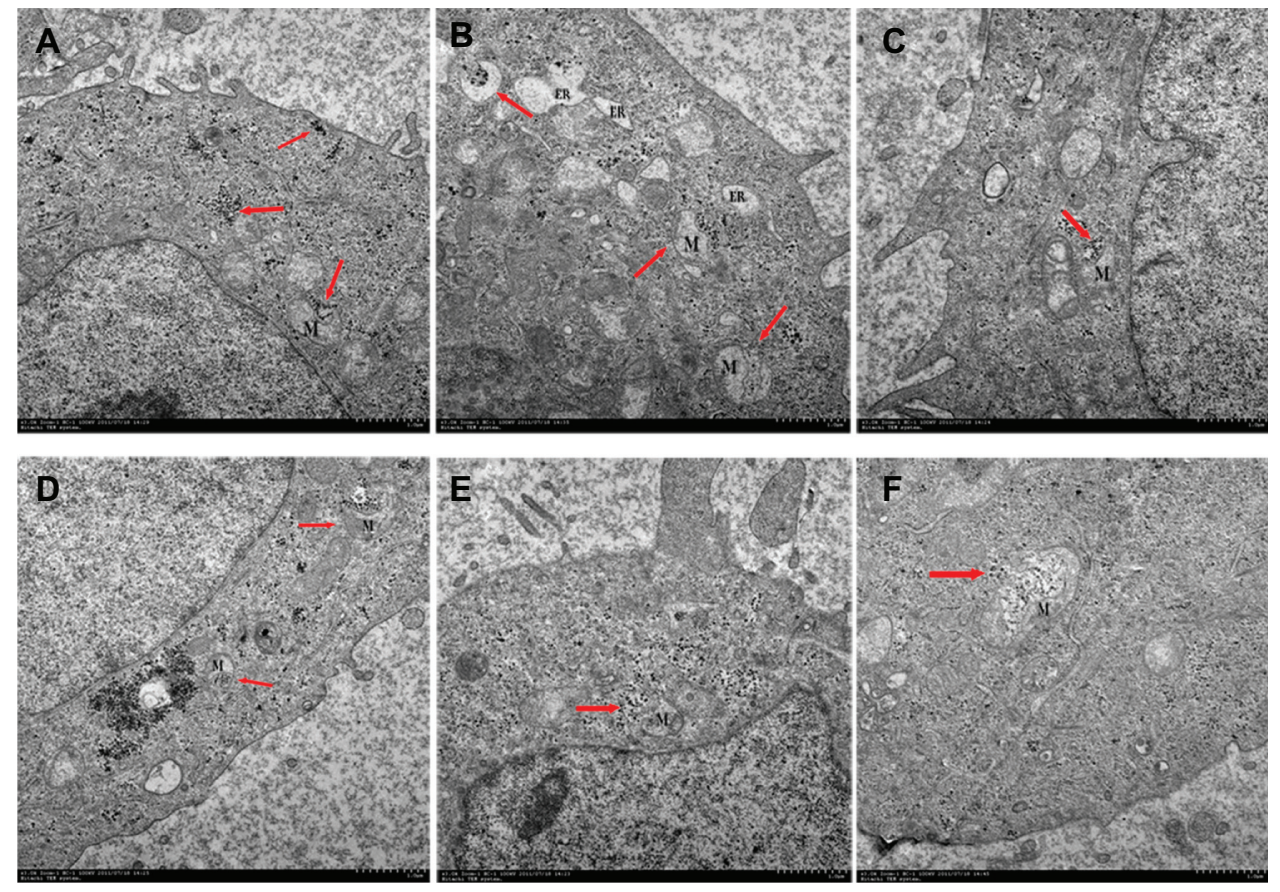

Figure 8 Transmission electron images of HeLa cells treated with a solution of CONPs $(30 \mu \mathrm{g} / \mathrm{mL})$ for 4 hours. The arrows indicate the accumulation of the CONPs. (A) The CONPs entered a mitochondrion and broke its outer membrane. CONPs existed in vesicles and in the cytoplasm. (B) The endoplasmic reticulum swelled visibly. A structure similar to an autophagy body phagocytized a group of CONPs. (C) The vesicles containing the CONPs appeared to target the outer membrane of the mitochondrion, and the shape of the mitochondrion had changed. (D) CONPs localized in small vesicles and entered or were entering the mitochondrion. (E and $\mathbf{F}$ ) CONPs broke the membrane of the mitochondrion and caused structural changes.

Abbreviations: CONPs, cuprous oxide nanoparticles; M, mitochondrion; ER, endoplasmic reticulum. 
Mitochondrial damage resulted in cytochrome $\mathrm{C}$ release and the formation of the apoptosome, a multimeric protein complex containing Apaf-1, cytochrome C, and caspase-9, which initiates the apoptotic pathway. Furthermore, damaging the mitochondria would result in a lack of energy and could lead to cell death.

Our research shows that CONPs could target the mitochondria and have selective toxicity against tumor cells. The inability to clear the CONPs might be one of the mechanisms to induce apoptosis of tumor cells selectively.

\section{Dithiothreitol protection experiment}

\section{and lipid peroxidation measurement}

ROS have a very close relationship with various vital movements and participate in immunological and pathological reactions, cell injury and death, and tumor generation. Recent researches have shown that metal oxide nanoparticles can exhibit spontaneous or light-activated ROS production, depending on the material composition and surface characteristics. ${ }^{15,36}$ To determine the role of ROS in cell death, DTT protection experiments and lipid peroxidation measurements were performed. DTT is commonly used in biochemical studies to prevent the oxidation of thiol groups and to reduce disulfides to dithiols, which can inactivate ROS. ${ }^{37-39}$ Our study results show that DTT could significantly prevent the cytotoxicity observed in cells treated with low concentrations of CONPs. However, DTT was unable to prevent significantly the cytotoxicity observed at higher concentrations $(P<0.01)$ (Figure 9). These studies indicate that the pharmacological

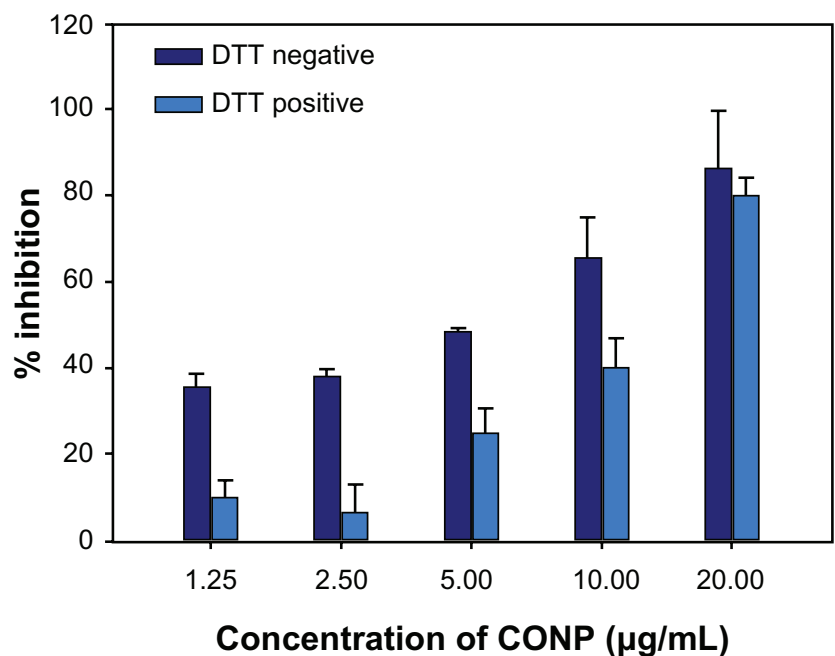

Figure 9 DTT protection experiment on HeLa cells for 48 hours. The MTT assay was then performed to evaluate protective effects of DTT.

Notes: The results show that DTT could increase cell viability at low concentrations but reduced viability at higher concentrations $(P<0.0$ I, $\mathrm{n}=3)$.

Abbreviations: CONPs, cuprous oxide nanoparticles; DTT, dithiothreitol; MTT, 3-(4,5-di-methylthiazol-2yl)-2,5-diphenyl tetrazolium bromide.

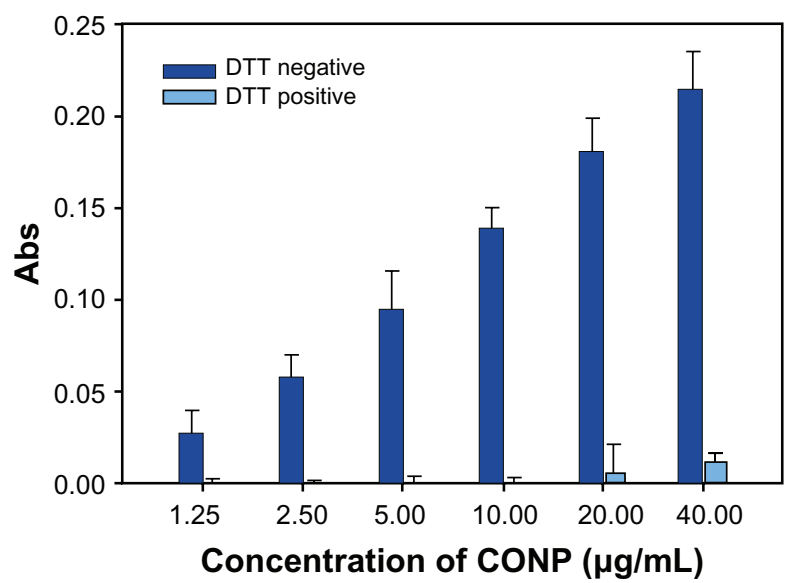

Figure 10 Lipid peroxidation measurement of CONPs in the liposomes prepared from soybean lecithin and cholesterol.

Notes: CONPs increased the lipid peroxidation activity and produced ROS, but DTT could significantly block the generation of $\operatorname{ROS}(P<0.01, n=3)$.

Abbreviations: CONPs, cuprous oxide nanoparticles; DTT, dithiothreitol; ROS, reactive oxygen species.

actions of CONPs might result from the generation of ROS, which in turn are responsible for inducing apoptosis.

To highlight ROS production, we performed lipid peroxidation experiments. The oxidation of fatty acids leads to the generation of lipid peroxides, thereby initiating a chain reaction that results in the disruption of the plasma and organelle membranes and subsequent cell death. Lipid peroxidation experiments show that DTT effectively inhibited the generation of the lipid peroxidation product malondialdehyde (MDA). MDA could be observed at low levels only when a concentration of greater than $20 \mu \mathrm{g} / \mathrm{mL}$ CONPs was used (Figure 10). However, higher levels of MDA were observed when DTT was not in the reaction mixture.

ROS can result in oxidative stress to cells, modulate the ability of thioredoxin (TRX) to interact and inhibit ASK1, and upregulate the JNK-, p38-, and p53-mediated signaling pathways, resulting in damaged lipids, proteins, DNA and other cellular components. ${ }^{6}$ Oxidative modifications of redox-sensitive transcription factors, including $\mathrm{NF}-\kappa \mathrm{B}$ and HIF-1 $\alpha$, and intermediate signaling molecules, such as PKC, ERK, JNK, and MAPKs, have also been shown to be involved in the ROS-mediated modulation of cell growth and survival. ${ }^{38,40}$ CONPs could induce the production of ROS and influence the vital movements of the cell. ROS were most likely involved in the apoptosis of tumor cells.

\section{Conclusion}

We investigated the selective cytotoxicity of CONPs on cancerous cells. CONPs can effectively induce apoptosis and suppress the cell cycle progression of tumor cells. By using TEM, we found that the CONPs could enter cells and 
specifically target the mitochondria, which may be one of the mechanisms by which CONPs induced apoptosis. We also examined the generation of ROS after treatment with CONPs and the effects of ROS on apoptosis using DTT protection and lipid peroxidation assays. The results indicate that CONPs could induce ROS production and increase lipid peroxidation. These changes might influence many cell signaling pathways and initiate apoptotic pathways.

Our work showed the potential utility of CONPs for the treatment of cancer owing to the selective toxicity of CONPs against tumor cells. However, further studies should be performed to learn more about the properties of these nanoparticles.

\section{Acknowledgments}

The authors would like to thank Xing-Hua Pan (Department of Genetics, Yale University, New Haven, CT), Yan Zhang, Guo-Ting Feng, and Fu Gao for their useful discussion and technical assistance with the sample analysis. The present study was financed by the National Basic Research Program of China (Grant Number: 2010CB945600, 2011CB966200, 2009CB941100), the National Natural Science Foundation of China (Grant Number: 30971462, 31171309 , 30600545), the National New Drug Development of Major Science and Technology Projects (Grant Number: 2011ZXJ09104-10C, 2009ZXJ09003-028), and the Creativity and Innovation Training Program of Second Military Medical University (Grant Number: MS2011039, MS2010075).

\section{Disclosure}

The authors report no conflicts of interest.

\section{References}

1. Service RF. Nanotechnology grows up. Science. 2004;18:1732-1734.

2. Sahoo SK, Parveen S, Panda JJ. The present and future of nanotechnology in human health care. Nanomedicine. 2007;3:20-31.

3. Twan L, Vladimir S, Karel U, et al. Polymeric nanomedicines for imageguided drug delivery and tumor-targeted combination therapy. Nano Today. 2010;5:197-212.

4. Yang F, Tang Q, Zhong X, et al. Surface decoration by Spirulina polysaccharide enhances the cellular uptake and anticancer efficacy of selenium nanoparticles. Int $J$ Nanomedicine. 2012;7:835-844.

5. Lee P, Zhang R, Li V, et al. Enhancement of anticancer efficacy using modified lipophilic nanoparticle drug encapsulation. Int J Nanomedicine. 2012;7:731-737.

6. Murphy EA, Majeti BK, Barnes LA, et al. Nanoparticle-mediated drug delivery to tumor vasculature suppresses metastasis. Proc Natl Acad Sci U S A. 2008; 105:9343-9348.

7. Siddiqui IA, Adhami VM, Christopher J, Chamcheu, Mukhtar H. Impact of nanotechnology in cancer: emphasis on nanochemoprevention. Int $J$ Nanomedicine. 2012;7:591-605.

8. Stevens MM, Ghadiali JE, Cohen BE. Protein kinase-actuated resonance energy transfer in quantum dot-peptide conjugates. ACS Nano. 2010;4: 4915-4919.
9. Durmus NG, Taylor EN, Inci F, et al. Fructose-enhanced reduction of bacterial growth on nanorough surfaces. Int $J$ Nanomedicine. 2012;7:537-545.

10. Shen S, Chow PS, Chen F, Tan RB. Submicron particles of SBA-15 modified with $\mathrm{MgO}$ as carriers for controlled drug delivery. Chem Pharm Bull. 2007;55:985-991.

11. Seo WS, Lee JH, Sun X, et al. FeCo/graphitic-shell nanocrystals as advanced magnetic-resonance-imaging and near-infrared agents. Nat Mater. 2006;5:971-976.

12. Visaria RK, Griffin RJ, Williams BW, et al. Enhancement of tumor thermal therapy using gold nanoparticle-assisted tumor necrosis factor-A delivery. Mol Cancer Ther. 2006;5:1014-1020.

13. Cartwright L, Poulsen MS, Nielsen HM, et al. In vitro placental model optimization for nanoparticle transport studies. Int $J$ Nanomedicine. 2012;7:497-510.

14. Neeshma D, Juewen L. Programmable assembly of DNA-functionalized liposomes by DNA. ACS Nano. 2011;5:1304-1312.

15. Mariappan P, Krishnamoorthy K, Kadarkaraithangam J, Govindasamy M. Selective toxicity of $\mathrm{ZnO}$ nanoparticles toward Gram-positive bacteria and cancer cells by apoptosis through lipid peroxidation. Nanomedicine. 2011;7:184-192.

16. Wu YN, Chen DH, Shi XY, et al. Cancer-cell-specific cytotoxicity of non-oxidized iron elements in iron core-gold shell NPs. Nanomedicine. 2011;7:420-427.

17. Becker AL, Orlotti NI, Folini M, et al. Redox-active polymer microcapsules for the delivery of a survivin-specific siRNA in prostate cancer cells. ACS Nano. 2011;5:1335-1344.

18. Xia T, Zhao Y, Sager T, et al. Decreased dissolution of $\mathrm{ZnO}$ by iron doping yields nanoparticles with reduced toxicity in the rodent lung and zebrafish embryos. ACS Nano. 2011;5:1223-1235.

19. Shen ZX, Shi ZZ, Fang J, et al. All-trans retinoic acid_As $\mathrm{O}_{3}$ combination yields a high quality remission and survival in newly diagnosed acute promyelocytic leukemia. Proc Natl Acad Sci U S A. 2004;101:5328-5335.

20. Chen Z, Wang ZY, Chen SJ. Acute promyelocytic leukemia: cellular and molecular basis of differentiation and apoptosis. Pharmacol Ther. 1997;76:141-149

21. Wang ZY, Chen Z. Differentiation and apoptosis induction therapy in acute promyelocytic leukemia. Lancet Oncol. 2000;1:101-106.

22. Qi WJ, Huang CZ, Chen LQ. Cuprous oxide nanospheres as probes for light scattering imaging analysis of live cells and for conformation identification of proteins. Talanta. 2010;80:1400-1405.

23. Liu P, Yang S, Fang M, Luo X, Cai W. Complex nanostructures synthesized from nanoparticle colloids under an external electric field. Nanoscale. 2011;1:3933-3940.

24. Yu G, Hu X, Liu D, et al. Electrodeposition of submicron/nanoscale $\mathrm{Cu}_{2} \mathrm{O} / \mathrm{Cu}$ junctions in an ultrathin $\mathrm{CuSO}_{4}$ solution layer. J Electroanal Chem. 2010;638:225-230.

25. Hassanien R, Al-Said SA, Siller L, et al. Smooth and conductive DNA-templated $\mathrm{Cu}_{2} \mathrm{O}$ nanowires: growth morphology, spectroscopic and electrical characterization. Nanotechnology. 2012;23:075601.

26. Yan XY, Tong XL, Zhang YF, et al. Cuprous oxide nanoparticles dispersed on reduced graphene oxide as an efficient electrocatalyst for oxygen reduction reaction. Chem Commun Camb. 2012;48:1892-1894.

27. Chi Y, Zhou S, Wan F. Flow cytometric analysis of the anticancer effects of copper acetate. Journal of China-Japan Friendship Hospital. 1994;8:63-66.

28. Daniel CJ, Casey CR, Miles FB, David NM, Rodney A. In vitro proliferating cell models to study cytotoxicity of silica nanowires. Nanomedicine. 2010;6:84-92.

29. Hajra KM, Liu JR. Apoptosome dysfunction in human cancer. Apoptosis. 2004;6:691-704.

30. Szeto HH. Cell-permeable, mitochondrial-targeted, peptide antioxidants. AAPS J. 2006;2:E277-E283.

31. AshaRani PV, Low KMG, Hande MP, Valiyaveettil S. Cytotoxicity and genotoxicity of silver nanoparticles in human cells. ACS Nano. 2009;3:279-290. 
32. Kumar R, Dwivedi PD, Dhawan A, Das M, Ansari KM. Citrinin-generated reactive oxygen species cause cell cycle arrest leading to apoptosis via the intrinsic mitochondrial pathway in mouse skin. Toxicol Sci. 2011;2:557-566.

33. Wang LM, Liu Y, Li W, Jiang XM, Chen CY. Selective targeting of gold nanorods at the mitochondria of cancer cells: implications for cancer therapy. Nano Lett. 2011;2:772-780.

34. Misawa M, Takahashi J. Generation of reactive oxygen species induced by gold nanoparticles under x-ray and UV irradiations. Nanomedicine. 2011;7:604-614.

35. Sauvain JJ, Riediker M, Deslarzes S. Nanoparticle reactivity toward dithiothreitol. Nanotoxicology. 2008;2:121-129.

36. Xia T, Kovochich M, Brant J, et al. Comparison of the abilities of ambient and manufactured nanoparticles to induce cellular toxicity according to an oxidative stress paradigm. Nano Lett. 2006;1:1794-1807.
37. Mehmet Z, Saim Ö, Tetsuya K, Toru S. A novel, simple, organic free preparation and characterization of water dispersible photoluminescent $\mathrm{Cu}_{2} \mathrm{O}$ nanocubes. Mater Lett. 2009;63:400-402.

38. Yong HH, Sung ZK, Suhn HK, Woo HP. Apoptosis in pyrogallol-treated Calu-6 cells is correlated with the changes of intracellular GSH levels rather than ROS levels. Lung Cancer. 2008;59:301-314.

39. Wu M, Huang J, Xu S, Ling T, Xie Y, Shen W. Reactive oxygen species (ROS) are essential mediators in epidermal growth factor (EGF)stimulated corneal epithelial cell proliferation, adhesion, migration, and wound healing. Exp Eye Res. 2009;89:876-886.

40. Kuo $\mathrm{CH}$, Michael $\mathrm{HH}$. Morphologically controlled synthesis of $\mathrm{Cu}_{2} \mathrm{O}$ nanocrystals and their properties. Nano Today. 2010;5:106-116. 


\section{Supplementary figure}

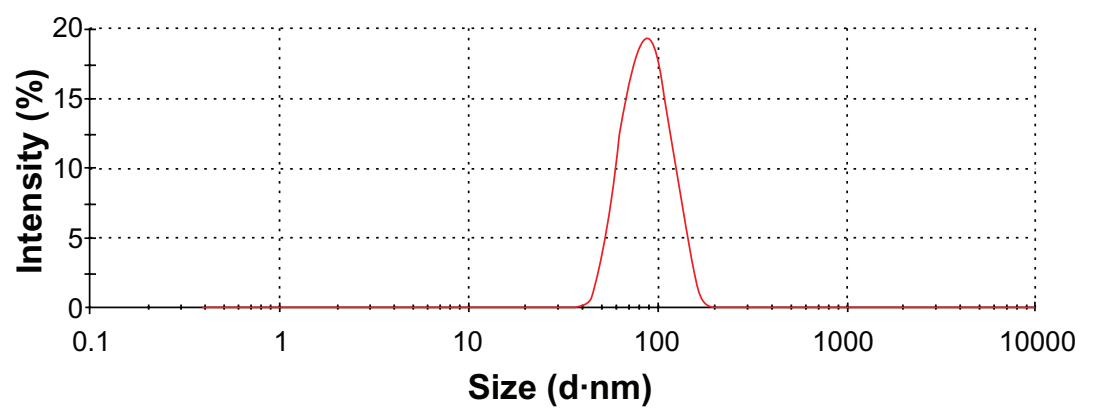

Figure SI Hydrodynamic size distributions of CONPs in water.

Note: The diameter of the CONPs ranged from approximately $40 \mathrm{~nm}$ to $110 \mathrm{~nm}$.

Abbreviation: CONPs, cuprous oxide nanoparticles.

\section{Publish your work in this journal}

The International Journal of Nanomedicine is an international, peerreviewed journal focusing on the application of nanotechnology in diagnostics, therapeutics, and drug delivery systems throughout the biomedical field. This journal is indexed on PubMed Central, MedLine, CAS, SciSearch ${ }^{\circledR}$, Current Contents ${ }^{\circledR} /$ Clinical Medicine,
Journal Citation Reports/Science Edition, EMBase, Scopus and the Elsevier Bibliographic databases. The manuscript management system is completely online and includes a very quick and fair peer-review system, which is all easy to use. Visit http://www.dovepress.com/ testimonials.php to read real quotes from published authors. 